\title{
Thermal Diffusion and Diffusion Thermo Effects on MHD Thermosolutal Marangoni Convection Boundary Layer Flow over a Permeable Surface
}

\author{
R. A. Hamid, ${ }^{1}$ W. M. K. A. Wan Zaimi, ${ }^{1}$ N. M. Arifin, ${ }^{2}$ \\ N. A. A. Bakar, ${ }^{1}$ and B. Bidin ${ }^{1}$ \\ ${ }^{1}$ Institute of Engineering Mathematics, Universiti Malaysia Perlis, Taman Bukit Kubu Jaya, Jalan Sarawak, \\ 02000 Kuala Perlis, Malaysia \\ ${ }^{2}$ Institute for Mathematical Research and Department of Mathematics, Universiti Putra Malaysia, \\ 43400 Serdang, Malaysia
}

Correspondence should be addressed to R. A. Hamid, rohanahamid@unimap.edu.my

Received 6 January 2012; Revised 1 March 2012; Accepted 15 March 2012

Academic Editor: Hiroshi Kanayama

Copyright (C) 2012 R. A. Hamid et al. This is an open access article distributed under the Creative Commons Attribution License, which permits unrestricted use, distribution, and reproduction in any medium, provided the original work is properly cited.

\begin{abstract}
The problem of thermal diffusion and diffusion thermo effects on thermosolutal Marangoni convection flow of an electrically conducting fluid over a permeable surface is investigated. Using appropriate similarity transformations, the governing system of partial differential equation is transformed to a set of nonlinear ordinary differential equations, then solved numerically using the Runge-Kutta-Fehlberg method. The effects of thermal diffusion and diffusion thermo, magnetic field parameter, thermosolutal surface tension ratio, and suction/injection parameter on the flow field, heat transfer characteristic, and concentration are thoroughly examined. Numerical results are obtained for temperature and concentration profiles as well as the local Nusselt and Sherwood numbers are presented graphically and analyzed. It is found that these governing parameters affect the variations of the temperature and concentration and also the local Nusselt and Sherwood numbers.
\end{abstract}

\section{Introduction}

The study of Marangoni convection has received great consideration in recent years in view of its application in industries. Marangoni convection is predictable to be very useful in wide area especially in crystal growth melts and semiconductor processing. The Marangoni boundary layer term was first initiated by Napolitano [1, 2] when studied the existence of the steady dissipative layers which occur along the liquid-liquid or liquid-gas interfaces. Marangoni convection induced by the surface tension gradient can be due to 
gradients of temperature (thermal convection) and/or concentration (solutal convection). A lot of analyses in Marangoni convection have been discovered in various geometries and conditions. Some of experimental works linked to Marangoni convection were discussed in several papers by Arafune and Hirata [3], Arafune et al. [4], Galazka and Wilke [5], Neumann et al. [6], Arendt and Eggers [7], and Xu et al. [8].

The related works to this present study were done by Al-Mudhaf and Chamkha [9] who obtained the similarity solution for MHD thermosolutal Marangoni convection over a flat surface in the presence of heat generation or absorption with fluid suction and injection. Christopher and Wang [10] have analyzed the effects of Prandtl number on Marangoni convection flow over a flat surface. Later, Pop et al. [11] studied numerically the problem of thermosolutal Marangoni forced convection over a permeable surface and this study continued by Hamid et al. [12] who obtained dual solutions of the problem. Chen [13] investigated the flow and the heat transfer characteristics on the forced convection in a power law liquid film under an applied Marangoni convection over a stretching sheet. Magyari and Chamkha [14] found solution for steady MHD thermosolutal Marangoni convection and present analytical solutions for velocity, temperature, and concentration field. Arifin et al. [15] added new dimension to the Marangoni convection problem by considering the steady thermosolutal marangoni mixed convection boundary layer flow under an external pressure gradient. The problem is solved using the shooting method. Most lately, Hamid et al. [16] studied the two-dimensional Marangoni convection flow past a flat plate in the presence of thermal radiation, suction, and injection effects.

Several papers that deal with flows in the presence Dufour or diffusion thermo effect and Soret or thermal diffusion effect are now presented. A brief literature on existence and development of Dufuor and Soret effects can be found in the papers by Kafoussias and Williams [17] and Puvi Arasu et al. [18]. Puvi Arasu et al. [18] investigated the impact of thermophoresis particles deposition on two-dimensional flow over a vertical stretching surface in the presence of chemical reaction and also Dufour and Soret effects taking place in the flow. The temperature gradients and concentration gradients play vital role in producing Dufour and Soret effects. The concentration gradient has generated the heat flux, namely, Dufour effect while mass flux is created by temperature gradients and is known as Soret effects. It is seem that the Charles Soret in 1879 is the first who found that a salt solution contained in a tube with two ends did not remain uniform in composition at different temperature. By this pioneering discovering, the term "Soret effect" officially introduced regarded his contribution on study of this particular effect. Later, the fundamental study on Soret effects remarkably grow over century (Osalusi et al. [19]).

The effects of thermal diffusion and diffusion thermo have been studied widely by several researchers due to its importance contribution in theory and practical. Some numerical studies on thermal diffusion and diffusion thermo effects include Afify [20] who studied the effects of thermal diffusion and diffusion thermo with suction and injection parameter on MHD free convection heat and mass transfer past a stretching sheet. Kafoussias and Williams [17] considered the mixed forced convection boundary layer flow with the effects of thermal diffusion and diffusion thermo in the presence of variable viscosity effect. This similar work continued by Eldabe et al. [21] for non-Newtonian power law fluid with the temperature dependent viscosity in the flow. Later, El-Aziz [22] considered the MHD three-dimensional free convection boundary layer flows past a stretching sheet with suction or injection and radiation in presence of Dufour and Soret effects. Next, Osalusi et al. [19] numerically studied the effects of thermal diffusion and diffusion thermo on combined heat and mass transfer of MHD convective and slip flow due to a rotating disk 
with the inclusion of viscous dissipation and Ohmic heating while Rashidi et al. [23] found its analytical solution using the homotopy analysis method (HAM). Most recently, Hayat et al. [24] obtained the series solutions for MHD two-dimensional axisymmetric flow of a second grade fluid with the existence of thermal diffusion and diffusion thermo effects, Joule heating and the chemical reaction effects.

The aim of this paper is to discuss the MHD thermosolutal Marangoni convection boundary layer over a permeable flat surface considering the effects of the thermal diffusion and diffusion thermo. The set of governing equations and boundary equation of the problem that are transformed into a set of nonlinear ordinary differential equation with assisting of similarity transformations are solved using the Runge-Kutta-Fehlberg method. The effects of different physical parameters on the temperature and concentration profiles as well as the local Nusselt and Sherwood numbers are presented. To verify the obtained results, we have compared the present numerical results with previous work by Al-Mudhaf and Chamkha [9]. The comparison results show a good agreement and we are confident that our present numerical results are accurate.

\section{Mathematical Formulation}

We consider the laminar boundary layer flow of an electrically conducting fluid over a permeable flat surface in the presence of Dufour and Soret effects. It is assumed that the mass flux velocity is $v_{w}$ with $v_{w}<0$ for suction and $v_{w}>0$ for injection, respectively. It is also assumed that a uniform magnetic field, $B_{0}$ is imposed in the direction normal to the surface. Then, the basic governing equation of the proposed problem (see Al-Mudhaf and Chamkha [9] and Afify [20]):

$$
\begin{gathered}
\frac{\partial u}{\partial x}+\frac{\partial v}{\partial y}=0 \\
u \frac{\partial u}{\partial x}+v \frac{\partial u}{\partial y}=v \frac{\partial^{2} u}{\partial y^{2}}-\frac{\sigma^{*} B_{0}^{2}}{\rho} u \\
u \frac{\partial T}{\partial x}+v \frac{\partial T}{\partial y}=\alpha \frac{\partial^{2} T}{\partial y^{2}}+\frac{D_{m} k_{T}}{c_{s} c_{p}} \frac{\partial^{2} h}{\partial y^{2}} \\
u \frac{\partial h}{\partial x}+v \frac{\partial h}{\partial y}=D_{m} \frac{\partial^{2} h}{\partial y^{2}}+\frac{D_{m} k_{T}}{T_{m}} \frac{\partial^{2} T}{\partial y^{2}}
\end{gathered}
$$

The surface tension $\sigma$ is assumed to vary linearly with the temperature $T$ and concentration $h$ as well as the wall temperature $T_{w}$ and concentration $h_{w}$ are presumed to be in quadratic functions of $x$. Hence, the boundary conditions of (2.1) is (see Al-Mudhaf and Chamkha [9])

$$
u=0, \quad v=v_{w}, \quad T=T_{\infty}+A x^{2}, \quad h=h_{\infty}+A^{*} x^{2}, \quad \mu \frac{\partial u}{\partial y}=\sigma_{T} \frac{\partial T}{\partial x}+\sigma_{h} \frac{\partial h}{\partial x} \text { on } y=0,
$$

$$
u \longrightarrow 0, T \longrightarrow T_{\infty}, h \longrightarrow h_{\infty} \text { as } y \longrightarrow \infty
$$


where $u, v$ are the components of velocity, respectively, in the $x$ and $y$ directions, $v$ is the kinematic viscosity, $\sigma^{*}$ is the fluid electrical conductivity, $\rho$ is the fluid density, and $\alpha$ is the thermal diffusivity. Besides, $D_{m}, k_{T}, c_{s}, c_{p}$, and $T_{m}$ are the diffusion coefficient, thermaldiffusion ratio, concentration susceptibility, specific heat at constant pressure, and mean fluid temperature, respectively (see Puvi Arasu et al. [18]). Moreover, $\mu$ is the dynamic viscosity, $\sigma_{T}$ and $\sigma_{h}$ are the rates of change of surface tension with temperature and solutal concentration while $A$ and $A^{*}$ are the temperature and concentration gradient coefficients, respectively.

The surface tension is defined as follow:

$$
\sigma=\sigma_{0}\left[1-\gamma_{T}\left(T-T_{\infty}\right)-\gamma_{h}\left(h-h_{\infty}\right)\right]
$$

where

$$
\gamma_{T}=-\frac{\partial \sigma}{\partial T}, \quad \gamma_{h}=-\frac{\partial \sigma}{\partial h}
$$

In order to find the similarity solutions of (2.1) subject to boundary conditions (2.2)-(2.3), we introduced the similarity variables (see Al-Mudhaf and Chamkha [9])

$$
\eta=C_{1} y, \quad f(\eta)=\frac{C_{2} \psi(x, y)}{x}, \quad \theta(\eta)=\frac{\left(T-T_{\infty}\right)}{A x^{2}}, \quad H(\eta)=\frac{\left(h-h_{\infty}\right)}{A^{*} x^{2}}
$$

and $\psi(x, y)$ is the stream function defined in usual way as $u=\partial \psi / \partial y$ and $v=-\partial \psi / \partial x$ where

$$
C_{1}=\sqrt[3]{\frac{\left.\rho A(d \sigma / d T)\right|_{h}}{\mu^{2}}}, \quad C_{2}=\sqrt[3]{\frac{\rho^{2}}{\left.\mu A(d \sigma / d T)\right|_{h}}},
$$

are the two similarity transformation coefficients.

Substituting (2.6)-(2.7) into (2.1), we obtained the following nonlinear ordinary differential equations:

$$
\begin{gathered}
f^{\prime \prime \prime}+f f^{\prime \prime}-f^{\prime 2}-M^{2} f^{\prime}=0, \\
\frac{1}{P r} \theta^{\prime \prime}+f \theta^{\prime}-2 f^{\prime} \theta+D_{f} H^{\prime \prime}=0, \\
\frac{1}{S c} H^{\prime \prime}+f H^{\prime}-2 f^{\prime} H+S_{r} \theta^{\prime \prime}=0,
\end{gathered}
$$

where a prime denotes a differentiation with respect to $\eta, D_{f}=D_{m} k_{T}\left(h_{w}-h_{\infty}\right) / c_{s} c_{p} v\left(T_{w}-T_{\infty}\right)$ and $S_{r}=D_{m} k_{T}\left(T_{w}-T_{\infty}\right) / T_{m} v\left(h_{w}-h_{\infty}\right)$ are the Dufour and Soret numbers, respectively. Here, $M$ is the magnetic field parameter, $P r$ is the Prandtl number, and $S c$ is the Schmidt number. 
It is important to mention that $f$ is the stream function similarity variable, $\theta$ and $H$ are the nondimensional temperature and concentration, respectively. The boundary conditions (2.2)(2.3) are reduced to

$$
\begin{gathered}
f(0)=f_{0}, \quad f^{\prime \prime}(0)=-2(1+r), \quad \theta(0)=1, \quad H(0)=1, \\
f^{\prime}(\infty)=0, \quad \theta(\infty)=0, \quad H(\infty)=0,
\end{gathered}
$$

where $r=\left.\Delta h(d \sigma / d h)\right|_{T} /\left.\Delta T(d \sigma / d T)\right|_{h}$ is the thermosolutal surface tension ratio.

The local Nusselt and Sherwood numbers are given by (see Al-Mudhaf and Chamkha [9])

$$
\begin{aligned}
& N u_{x}=\frac{q^{\prime \prime}(x) x}{\lambda\left(T_{w}-T_{\infty}\right)}=-C_{1} x \theta^{\prime}(0), \\
& S h_{x}=\frac{h^{\prime \prime}(x) x}{D\left(T_{w}-T_{\infty}\right)}=-C_{1} x H^{\prime}(0),
\end{aligned}
$$

where $D$ is the mass diffusivity, $q^{\prime \prime}$ is the heat flux, and $h^{\prime \prime}$ is the mass flux.

\section{Results and Discussion}

Numerical solutions of the ordinary differential equations (2.8)-(2.10) that subject to boundary conditions (2.11) have been solved using the Runge-Kutta-Fehlberg fourthfifth order (RKF45) method using Maple 12 and the algorithm RKF45 in Maple has been well tested for its accuracy and robustness (Aziz [25]). In this method, it is most important to choose the appropriate finite value of the edge of boundary layer, $\eta \rightarrow \infty$ (say $\eta_{\infty}$ ) that is between 4 to 10 , which is in accordance with the standard practice in the boundary layer analysis. The influences of the magnetic field parameter $(M)$, the suction/injection parameter $\left(f_{0}\right)$, the thermosolutal surface tension ratio $(r)$, the combined Dufour number $D_{f}$ and Soret number $S_{r}$ on the velocity, temperature and concentration, and the Nusselt and Sherwood numbers are presented in tables and some graphs. These findings are summarized and presented in the Tables 1-4 and Figures 1-9. We have compared the present results with the results attained by Al-Mudhaf and Chamkha [9] when the heat generation/absorption and first-order chemical reaction effects are neglected. It is seen that the results presented in Tables 1-3 are in very well agreement. Hence, this leads the confidence of the present results. It should be mentioned that $f^{\prime}(0),-\theta^{\prime}(0)$ and $-H^{\prime}(0)$ are related to the surface velocity, Nusselt number, and Sherwood numbers, respectively.

Figures 1, 2, and 3 display the velocity, temperature, and concentration profiles for different values of magnetic field parameter $M$ when the other parameters are fixed. An application of a magnetic field within boundary layer has produced resistive-type force which known as Lorentz force. This force acts to retard the fluid motion along surface and 
Table 1: Comparison values of $f^{\prime}(0),-\theta^{\prime}(0)$ and $-H^{\prime}(0)$ with different parameter $M$.

\begin{tabular}{|c|c|c|c|c|c|c|}
\hline \multirow{2}{*}{$M$} & \multicolumn{2}{|l|}{$f^{\prime}(0)$} & \multicolumn{2}{|l|}{$-\theta^{\prime}(0)$} & \multicolumn{2}{|c|}{$-H^{\prime}(0)$} \\
\hline & $\begin{array}{c}\text { Al-Mudhaf and } \\
\text { Chamkha [9] }\end{array}$ & Present & $\begin{array}{c}\text { Al-Mudhaf and } \\
\text { Chamkha [9] }\end{array}$ & Present & $\begin{array}{c}\text { Al-Mudhaf and } \\
\text { Chamkha [9] }\end{array}$ & Present \\
\hline 0 & 1.587671 & 1.587401 & 1.442203 & 1.442069 & 1.220880 & 1.220731 \\
\hline 1 & 1.315181 & 1.314596 & 1.206468 & 1.205891 & 1.005541 & 1.005808 \\
\hline 2 & 0.903945 & 0.9032119 & 0.7596045 & 0.7625145 & 0.6106418 & 0.6188354 \\
\hline 3 & 0.6448883 & 0.6440222 & 0.4422402 & 0.4625877 & 0.3473967 & 0.37638077 \\
\hline 4 & 0.4933589 & 0.4924782 & 0.2728471 & 0.3114736 & 0.2127706 & 0.25873328 \\
\hline
\end{tabular}

Table 2: Comparison values of $f^{\prime}(0),-\theta^{\prime}(0)$ and $-H^{\prime}(0)$ with different parameter $f_{0}$.

\begin{tabular}{lcccccc}
\hline$f_{0}$ & \multicolumn{2}{c}{$f^{\prime}(0)$} & \multicolumn{2}{c}{$-\theta^{\prime}(0)$} & \multicolumn{2}{c}{$-H^{\prime}(0)$} \\
& $\begin{array}{c}\text { Al-Mudhaf and } \\
\text { Chamkha [9] }\end{array}$ & Present & $\begin{array}{c}\text { Al-Mudhaf and } \\
\text { Chamkha [9] }\end{array}$ & Present & $\begin{array}{c}\text { Al-Mudhaf and } \\
\text { Chamkha [9] }\end{array}$ & Present \\
\hline-2 & 2.383451 & 2.382975 & 1.251341 & 1.250618 & 1.129218 & 1.128784 \\
-1 & 2.000379 & 1.999999 & 1.336441 & 1.335853 & 1.173002 & 1.173006 \\
0 & 1.587671 & 1.58740104 & 1.442203 & 1.442067 & 1.220880 & 1.220715 \\
1 & 1.179708 & 1.17950902 & 1.634990 & 1.634360 & 1.328699 & 1.327979 \\
2 & 0.8480268 & 0.8477075 & 2.020949 & 2.019468 & 1.593570 & 1.592596 \\
\hline
\end{tabular}

Table 3: Comparison values of $f^{\prime}(0),-\theta^{\prime}(0)$ and $-H^{\prime}(0)$ with different parameter $r$.

\begin{tabular}{ccccccc}
\hline \multicolumn{2}{c}{$f^{\prime}(0)$} & \multicolumn{3}{c}{$-\theta^{\prime}(0)$} & \multicolumn{2}{c}{$-H^{\prime}(0)$} \\
& $\begin{array}{c}\text { Al-Mudhaf and } \\
\text { Chamkha [9] }\end{array}$ & $\begin{array}{c}\text { Present } \\
(2011)\end{array}$ & $\begin{array}{c}\text { Al-Mudhaf and } \\
\text { Chamkha [9] }\end{array}$ & $\begin{array}{c}\text { Present } \\
(2011)\end{array}$ & $\begin{array}{c}\text { Al-Mudhaf and } \\
\text { Chamkha [9] }\end{array}$ & $\begin{array}{c}\text { Present } \\
(2011)\end{array}$ \\
\hline 0 & 1.587582 & 1.587297 & 1.442247 & 1.442412 & 1.220880 & 1.222427 \\
1 & 2.520988 & 2.519819 & 1.817826 & 1.816999 & 1.538960 & 1.538688 \\
5 & 5.244303 & 5.241482 & 2.621562 & 2.620417 & 2.219093 & 2.218261 \\
\hline
\end{tabular}

Table 4: The values of $-\theta^{\prime}(0)$ and $-H^{\prime}(0)$ with different parameters $D_{f}$ and $S_{r}$.

\begin{tabular}{lccc}
\hline$D_{f}$ & $S_{r}$ & $-\theta^{\prime}(0)$ & $-H^{\prime}(0)$ \\
\hline 0.03 & 2.0 & 1.624748 & -0.00587659 \\
0.06 & 1.0 & 1.603973 & 0.6866464 \\
0.15 & 0.4 & 1.541646 & 1.102160 \\
0.3 & 0.2 & 1.437767 & 1.240664 \\
0.6 & 0.1 & 1.230011 & 1.309917 \\
2.0 & 0.03 & 0.260478 & 1.358394 \\
\hline
\end{tabular}




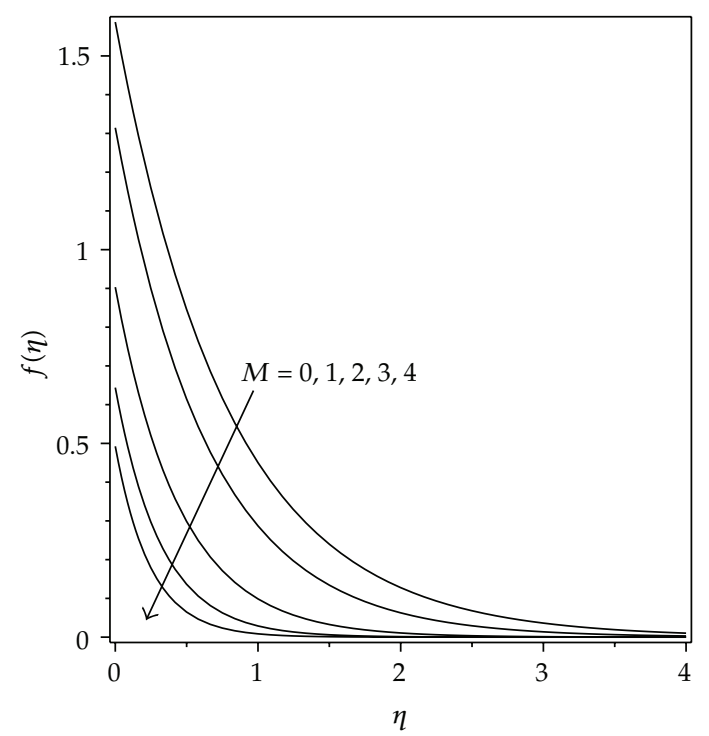

Figure 1: Velocity profiles for different values of $M$ when $P r=0.78, S c=0.6, D_{f}=0.03, S_{r}=2, r=0$, and $f_{0}=0$.

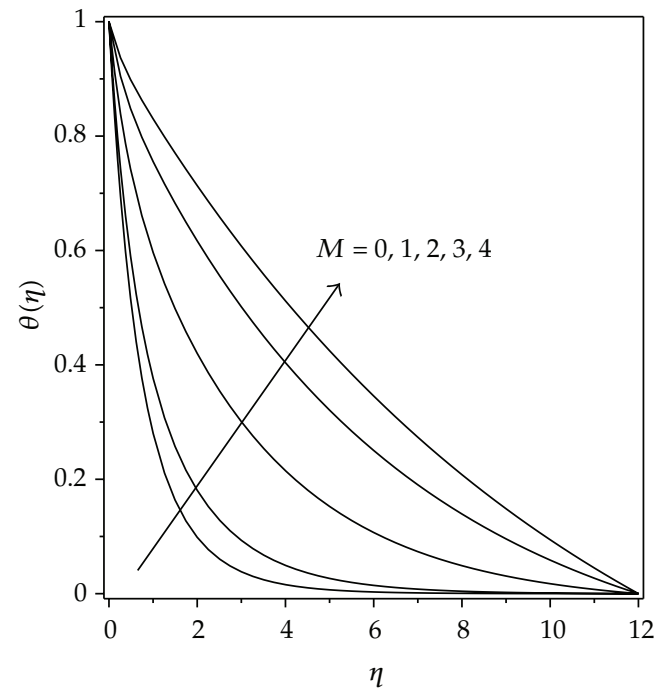

Figure 2: Temperature profiles for different values of $M$ when $P r=0.78, S c=0.6, D_{f}=0.03, S_{r}=2, r=0$, and $f_{0}=0$.

simultaneously increases its temperature and concentration values. In addition, the effect of the magnetic parameter of the viscous shearing force and the Lorentz force is given by

$$
v \frac{u}{\delta_{v}^{2}} \approx \frac{\delta^{*} B_{0}^{2}}{\rho} u .
$$




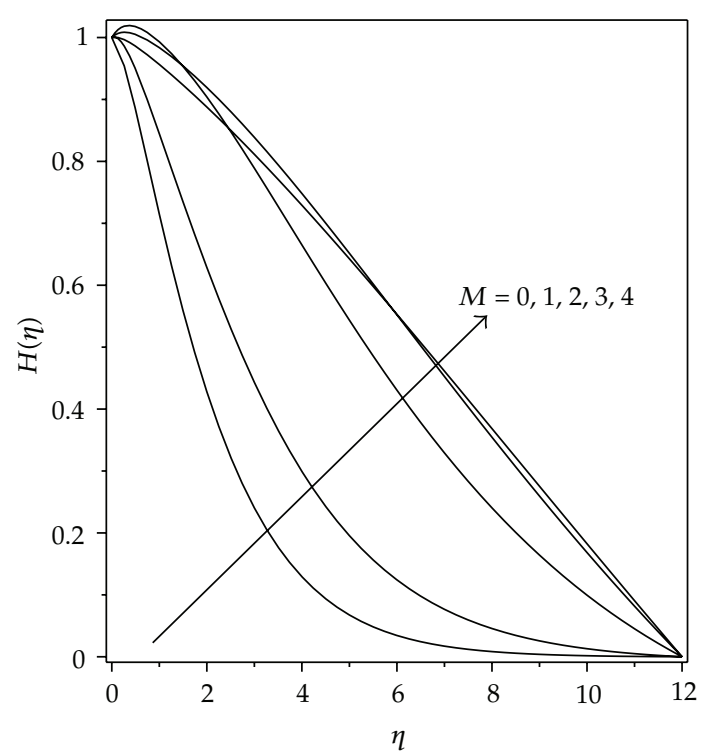

Figure 3: Concentration profiles for different values of $M$ when $P r=0.78, S c=0.6, D_{f}=0.03, S_{r}=2$, $r=0$, and $f_{0}=0$.

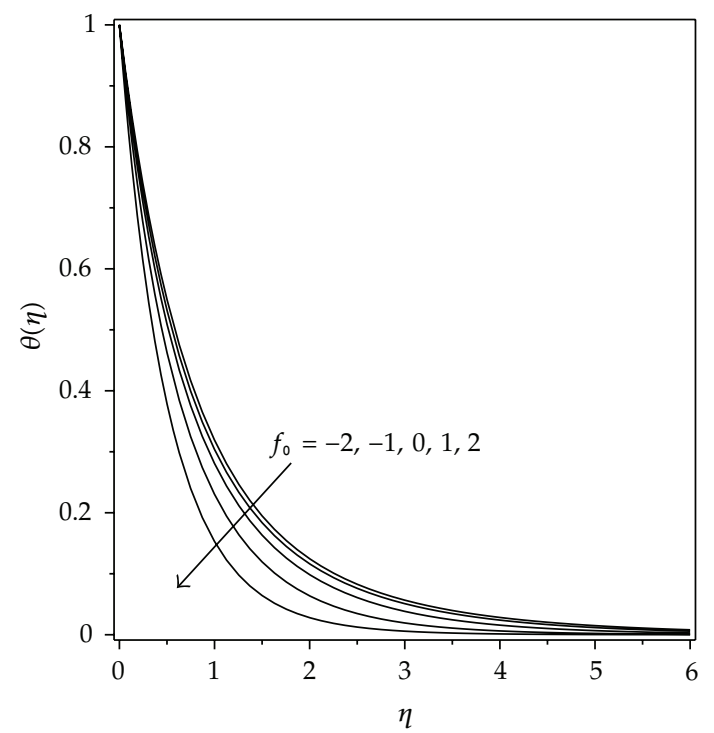

Figure 4: Temperature profiles for different values of $f_{0}$ when $P r=0.78, S c=0.6, D_{f}=0.03, S_{r}=2, r=0$, and $M=0$.

Thus, (3.1) gives

$$
\eta_{V} \approx \frac{1}{M}
$$

However, the effect of surface tension can be obtained from (2.2) by the relation

$$
v \frac{u}{\delta_{v}} \approx\left(\sigma_{T} 2 A x+\sigma_{h} A^{*} x\right)
$$




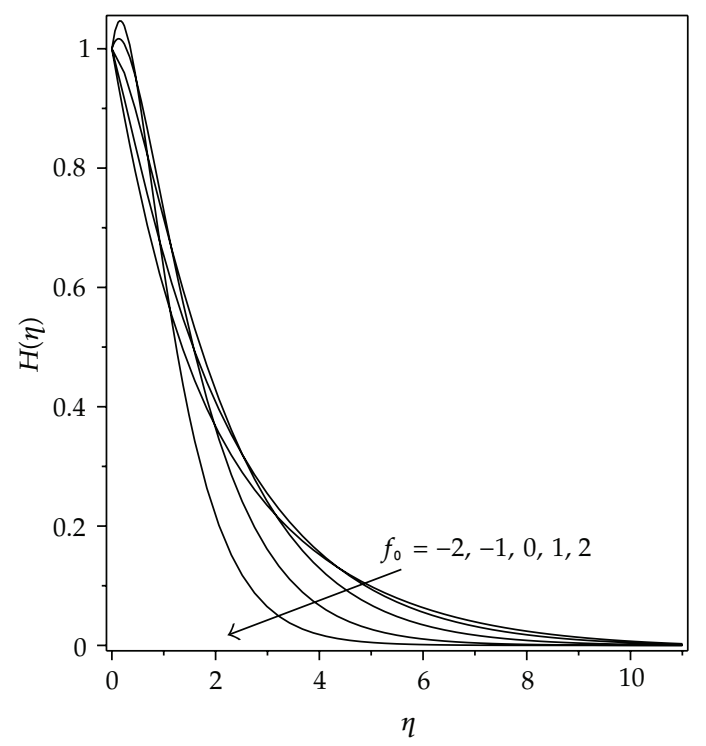

Figure 5: Concentration profiles for different values of $f_{0}$ when $\operatorname{Pr}=0.78, S c=0.6, D_{f}=0.03, S_{r}=2, r=0$, and $M=0$.

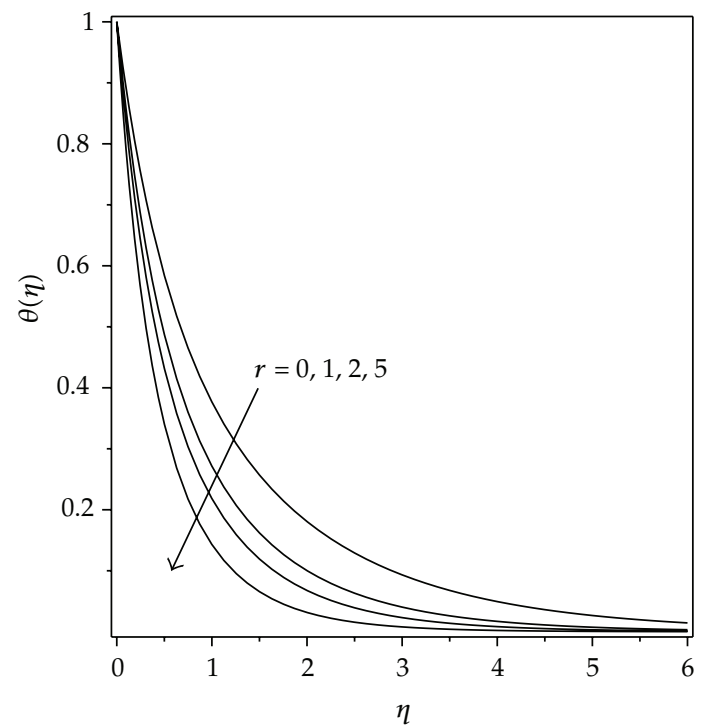

Figure 6: Temperature profiles for different values of $r$ when $\operatorname{Pr}=0.78, S_{c}=0.6, D_{f}=0.03, S_{r}=2, M=1$, and $f_{0}=0$.

Then, (3.3) becomes

$$
f^{\prime}(0) \approx 2(1+r) \eta_{V} \approx \frac{2(1+r)}{M} .
$$

Therefore, one can see that the velocity boundary layer thickness decreases with the increase of $M$ as shown in Figure 1. However, the temperature and concentration increase 


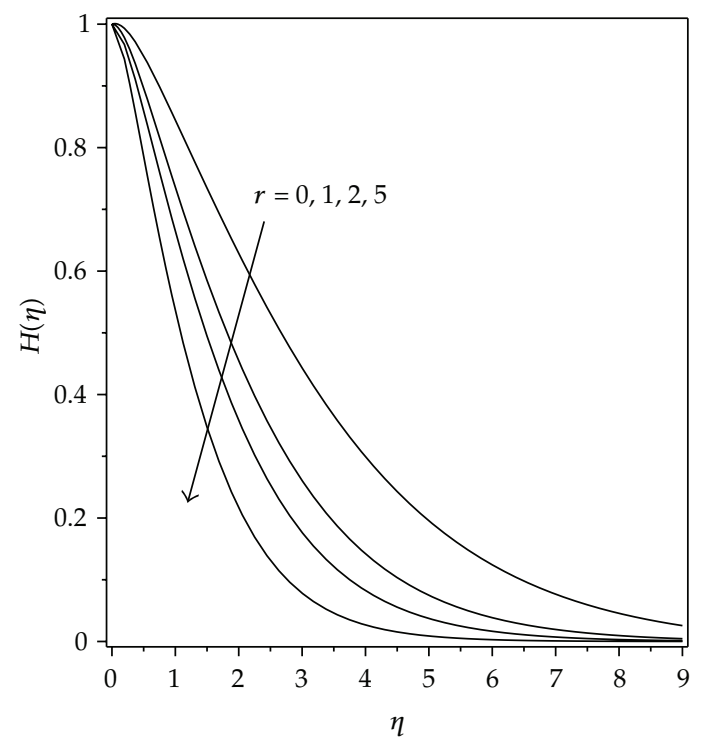

Figure 7: Concentration profiles for different values of $r$ when $\operatorname{Pr}=0.78, S c=0.6, D_{f}=0.03, S_{r}=2, M=1$, and $f_{0}=0$.

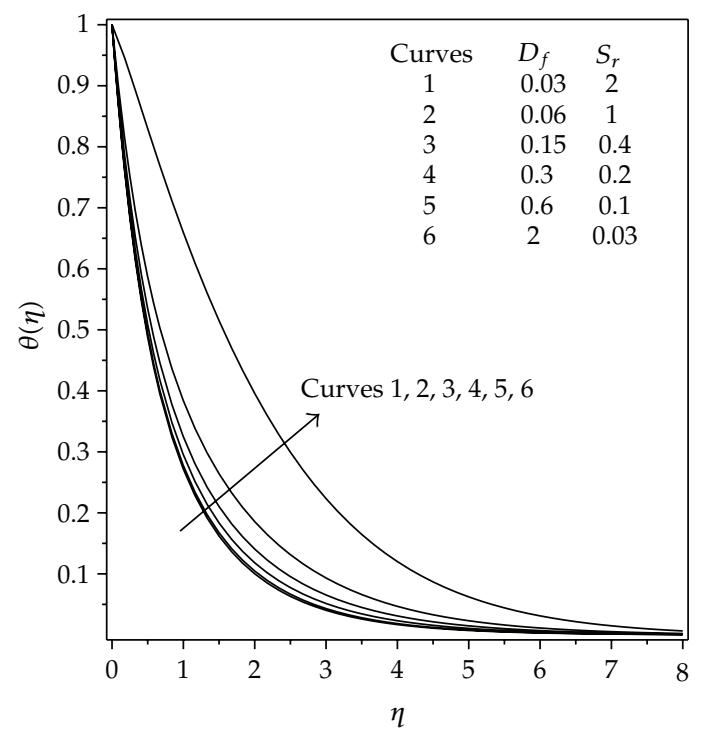

Figure 8: Temperature profiles for different values of $D_{f}$ and $S_{r}$ when $\operatorname{Pr}=0.78, S c=0.6, r=1, M=1$, and $f_{0}=0$.

with the increasing of the magnetic field parameter $M$. The temperature and concentration profiles are also affected by $\mathrm{Pr}, S_{c}, D_{f}$, and $S_{r}$. Figures 4 and 5 show the influences of the suction and injection parameter $f_{0}$ on the temperature and concentration profiles. The results point out that increasing values in suction parameter $\left(f_{0}>0\right)$ at the wall tend to decrease the temperature of the flow as shown in the Figure 4. Concurrently, the concentration profiles decrease as well with the inclusion of the suction parameter. This phenomenon is caused by 


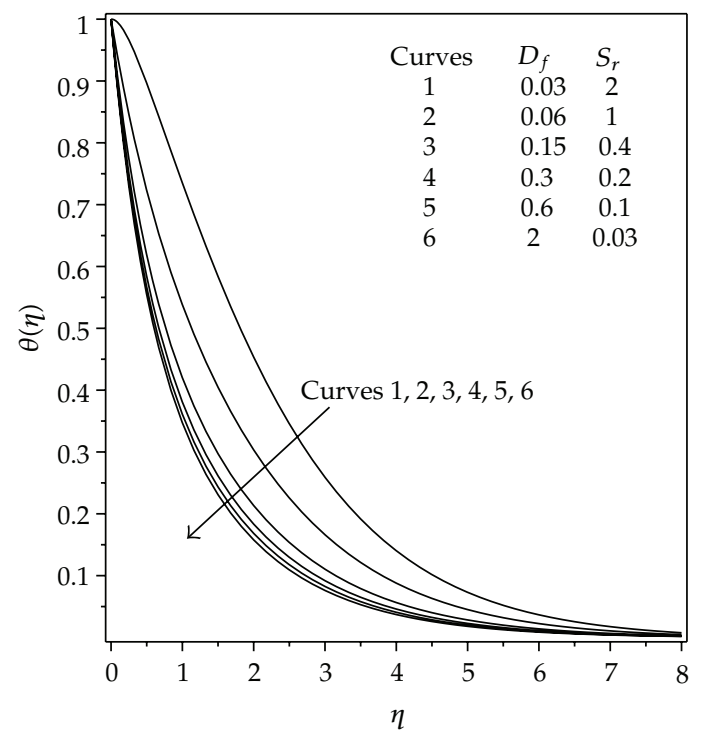

Figure 9: Concentration profiles for different values of $D_{f}$ and $S_{r}$ when $\operatorname{Pr}=0.78, S c=0.6, r=1, M=1$, and $f_{0}=0$.

the fluid moves nearer to the surface and decreases the thermal and concentration boundary layer thickness. Conversely, these observations are found to be opposite in the case of injection $\left(f_{0}<0\right)$. It is seen that the imposition of the injection parameter will increase the fluid temperature and concentration.

The effect of the inclusion of the thermosolutal surface tension ratio $r$ on the temperature and concentration profiles is illustrated in Figures 6 and 7, respectively. We observed that the parameter $r$ significantly decreases the fluid temperature and concentration. This finding is obtained due to the increase of the Marangoni convection effect as $r$ increases. From physical point of view, by increasing the Marangoni convection effect, more induced flows are produced. As consequences, the resulting flows will propagate within the boundary layers impling the maximum velocity obtained at the wall.

Figures 8 and 9 show the combination effects of the Dufour and Soret numbers on the fluid temperature and concentration. The Dufour $D_{f}$ and Soret $S_{r}$ numbers represent the thermal diffusion and diffusion thermal effects in this problem. Moreover, we have to be discriminating in selection of Dufour and Soret numbers in order to guarantee that the product of $S_{r} D_{f}$ is kept constant as well as assuming the mean temperature $T_{m}$ is constant. To be practical, the Dufour and Soret values that are used in the present study are referred to the paper reported by Kafoussias and Williams [17]. Figure 8 specifically shows the influences of the Dufour and Soret number on the variations of the fluid temperature. For the case of increasing Dufour number and decreasing Soret number, it is seen that the temperature profiles show dissimilar increasing on its values. The Dufour term that describes the effect of concentration gradients as underlined in (2.9) plays a vital role in assisting the flow and is able to increase thermal energy in the boundary layer. This is the evident that as the parameter $D_{f}$ increases and $S_{r}$ decreases, the fluid temperature will increase.

In Figure 9, increasing Dufour number and simultaneously decreasing Soret number have implied significant effects on the concentration profiles. The Soret term exemplifies the 
temperature gradient effects on the variation of concentration as noted in (2.10). It is observed as the Dufour number increases and Soret number is decreased, the concentration values are found to decrease. For a small Soret number $S_{r}<0.4$, it is seen that the concentration values decrease steadily and closely to each other with similar pattern. On the other hand, these observations are found to be contrary in the case of $S_{r}>1$ when the graph shows large differences in concentration values compared to curves (3-5) with low values of Soret number. The physical reason of this phenomena that occurs is due to a strong concentration overshoot that happens nearly to the surface.

Furthermore, the results in the Figures 8 and 9 agree well with the data in Table 4 . We can see that combination effects of the thermal diffussion and diffusion thermo can reduce the surface temperature gradient while increase the surface concentration gradient. Hence, the local Nusselt number decreases and the local Sherwood number increases by increasing the Dufour number and reducing the Soret number.

\section{Conclusions}

The problem of thermal diffusion and diffusion thermo effects on thermosolutal Marangoni convection boundary layer flow over a flat surface considering the fluid suction and injection in the presence of the magnetic field is studied. The governing partial differential equations associated with the boundary conditions were transformed into nonlinear ordinary differential equations before being solved using the Runge-Kutta-Fehlberg method. The effects of thermal diffusion (Soret number $S_{r}$ ) and diffusion thermo (Dufour number $D_{f}$ ), magnetic field parameter $M$, thermosolutal surface tension ratio $r$ and suction or injection parameter $f_{0}$ on the velocity, temperature and concentration field, and the physical quantities interest in engineering problem such as surface velocity, the local Nusselt number and Sherwood number were plotted, tabulated, and analyzed. It is found that the inclusion of the magnetic field parameter on the flow increased the temperature, and concentration profiles while it decreased the velocity field as well as Nusselt an Sherwood numbers. The analysis also revealed that the same behavior was drawn as thermosolutal surface tension ratio $r$ was decreased. We also observed that increasing the suction parameter $f_{0}$ has decreased the fluid velocity, temperature and concentration profiles as it increased the Nusselt and Sherwood numbers. In contrast, the opposite observation was attained for the imposition of the injection parameter. The current analysis also signifies that the temperature profile and Sherwood number increase with the increasing in Dufour number and decreasing in Soret number. Opposite behavior is identified on Nusselt number and concentration profile. We also noticed that the velocity field is insensitive by changing in Dufour and Soret numbers.

\section{Acknowledgment}

This work was supported by research grants from the Ministry of Higher Education, Malaysia (project code: FRGS/1/2011/SG/UNIMAP/03/7).

\section{References}

[1] L. G. Napolitano, "Microgravity fluid dynamics," in Proceedings of the 2nd Levitch Conference, Washington, DC, USA, 1978. 
[2] L. G. Napolitano, "Marangoni boundary layers," in Proceedings of the 3rd European Symposium on Materials Sciences in Space, Grenoble, France, 1979.

[3] K. Arafune and A. Hirata, "Thermal and solutal marangoni convection in In-Ga-Sb system," Journal of Crystal Growth, vol. 197, no. 4, pp. 811-817, 1999.

[4] K. Arafune, K. Yamamoto, and A. Hirata, "Interactive thermal and solutal Marangoni convection during compound semiconductor growth in a rectangular open boat," International Journal of Heat and Mass Transfer, vol. 44, no. 13, pp. 2404-2411, 2001.

[5] Z. Galazka and H. Wilke, "Influence of Marangoni convection on the flow pattern in the melt during growth of $\mathrm{Y}_{3} \mathrm{Al}_{5} \mathrm{O}_{12}$ single crystals by the Czochralski method," Journal of Crystal Growth, vol. 216, no. 1, pp. 389-398, 2000.

[6] H. Neumann, Y. Plevachuk, and F. Allenstein, "Investigation of Marangoni convection in monotectic melts by resistance measurements," Materials Science and Engineering A, vol. 361, no. 1-2, pp. 155-164, 2003.

[7] B. Arendt and R. Eggers, "Interaction of Marangoni convection with mass transfer effects at droplets," International Journal of Heat and Mass Transfer, vol. 50, no. 13-14, pp. 2805-2815, 2007.

[8] Y. L. Xu, Z. B. Dong, Y. H. Wei, and C. L. Yang, "Marangoni convection and weld shape variation in A-TIG welding process," Theoretical and Applied Fracture Mechanics, vol. 48, no. 2, pp. 178-186, 2007.

[9] A. Al-Mudhaf and A. J. Chamkha, "Similarity solutions for MHD thermosolutal Marangoni convection over a flat surface in the presence of heat generation or absorption effects," Heat and Mass Transfer, vol. 42, no. 2, pp. 112-121, 2005.

[10] D. M. Christopher and B. Wang, "Prandtl number effects for Marangoni convection over a flat surface," International Journal of Thermal Sciences, vol. 40, no. 6, pp. 564-570, 2001.

[11] I. Pop, A. Postelnicu, and T. Groşan, "Thermosolutal Marangoni forced convection boundary layers," Meccanica, vol. 36, no. 5, pp. 555-571, 2001.

[12] R. A. Hamid, N. M. Arifin, R. Nazar, F. M. Ali, and I. Pop, "Dual solutions on thermosolutal Marangoni forced convection boundary layer with suction and injection," Mathematical Problems in Engineering, vol. 2011, Article ID 875754, 19 pages, 2011.

[13] C. H. Chen, "Marangoni effects on forced convection of power-law liquids in a thin film over a stretching surface," Physics Letters A, vol. 370, no. 1, pp. 51-57, 2007.

[14] E. Magyari and A. J. Chamkha, "Exact analytical results for the thermosolutal MHD Marangoni boundary layers," International Journal of Thermal Sciences, vol. 47, no. 7, pp. 848-857, 2008.

[15] N. M. Arifin, F. M. Ali, R. Nazar, and I. Pop, "Thermal and solutal marangoni mixed convection boundary layer flow," WSEAS Transactions on Mathematics, vol. 9, no. 5, pp. 376-385, 2010.

[16] R. A. Hamid, N. M. Arifin, R. Nazar, and F. M. Ali, "Radiation effects on marangoni convection over a flat surface with suction and injection," Malaysian Journal of Mathematical Sciences, vol. 5, no. 1, pp. 13-25, 2011.

[17] N. G. Kafoussias and E. W. Williams, "Thermal-diffusion and diffusion-thermo effects on mixed freeforced convective and mass transfer boundary layer flow with temperature dependent viscosity," International Journal of Engineering Science, vol. 33, no. 9, pp. 1369-1384, 1995.

[18] P. Puvi Arasu, P. Loganathan, R. Kandasamy, and I. Muhaimin, "Lie group analysis for thermaldiffusion and diffusion-thermo effects on free convective flow over a porous stretching surface with variable stream conditions in the presence of thermophoresis particle deposition," Nonlinear Analysis: Hybrid Systems, vol. 5, no. 1, pp. 20-31, 2011.

[19] E. Osalusi, J. Side, and R. Harris, "Thermal-diffusion and diffusion-thermo effects on combined heat and mass transfer of a steady MHD convective and slip flow due to a rotating disk with viscous dissipation and Ohmic heating," International Communications in Heat and Mass Transfer, vol. 35, no. 8, pp. 908-915, 2008.

[20] A. A. Afify, "Similarity solution in MHD: effects of thermal diffusion and diffusion thermo on free convective heat and mass transfer over a stretching surface considering suction or injection," Communications in Nonlinear Science and Numerical Simulation, vol. 14, no. 5, pp. 2202-2214, 2009.

[21] N. T. Eldabe, A. G. El-Saka, and A. Fouad, "Thermal-diffusion and diffusion-thermo effects on mixed free-forced convection and mass transfer boundary layer flow for non-Newtonian fluid with temperature dependent viscosity," Applied Mathematics and Computation, vol. 152, no. 3, pp. 867-883, 2004.

[22] M. A. El-Aziz, "Thermal-diffusion and diffusion-thermo effects on combined heat and mass transfer by hydromagnetic three-dimensional free convection over a permeable stretching surface with radiation," Physics Letters A, vol. 372, no. 3, pp. 263-272, 2008. 
[23] M. M. Rashidi, T. Hayat, E. Erfani, S. A. Mohimanian Pour, and A. A. Hendi, "Simultaneous effects of partial slip and thermal-diffusion and diffusion-thermo on steady MHD convective flow due to a rotating disk," Communications in Nonlinear Science and Numerical Simulation, vol. 16, no. 11, pp. 4303-4317, 2011.

[24] T. Hayat, M. Nawaz, S. Asghar, and S. Mesloub, "Thermal-diffusion and diffusion-thermo effects on axisymmetric flow of a second grade fluid," International Journal of Heat and Mass Transfer, vol. 54, no. 13-14, pp. 3031-3041, 2011.

[25] A. Aziz, "A similarity solution for laminar thermal boundary layer over a flat plate with a convective surface boundary condition," Communications in Nonlinear Science and Numerical Simulation, vol. 14, no. 4, pp. 1064-1068, 2009. 


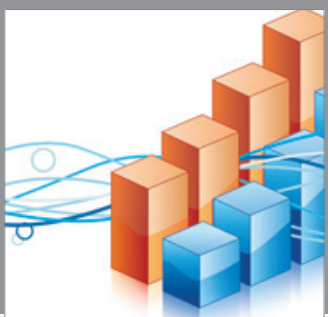

Advances in

Operations Research

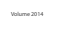

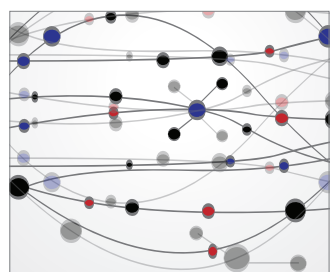

\section{The Scientific} World Journal
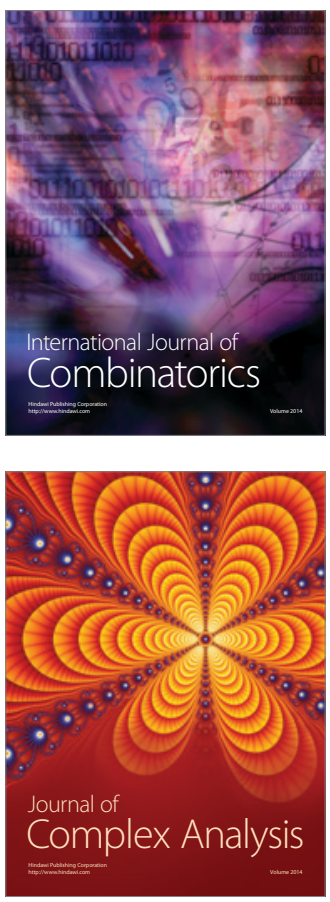

International Journal of

Mathematics and

Mathematical

Sciences
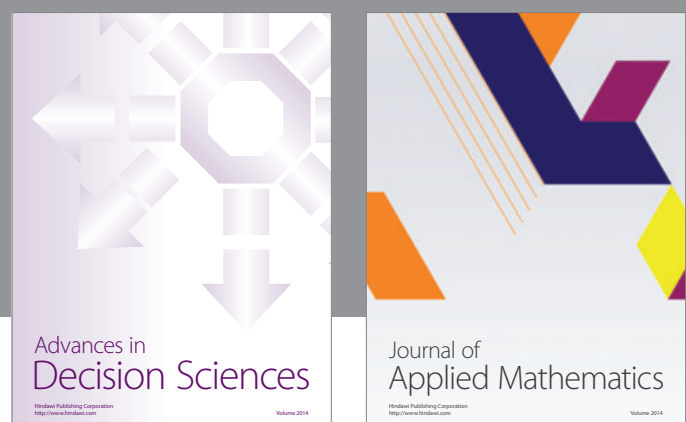

Journal of

Applied Mathematics
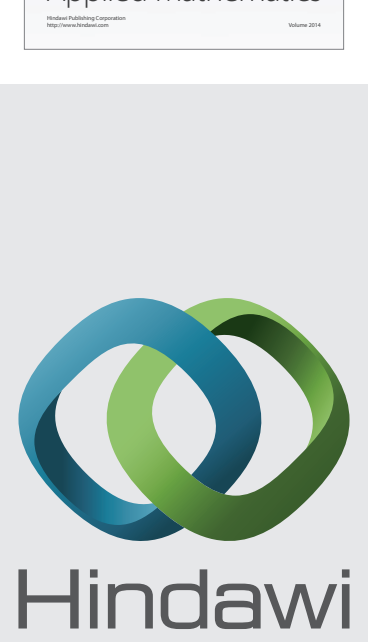

Submit your manuscripts at http://www.hindawi.com
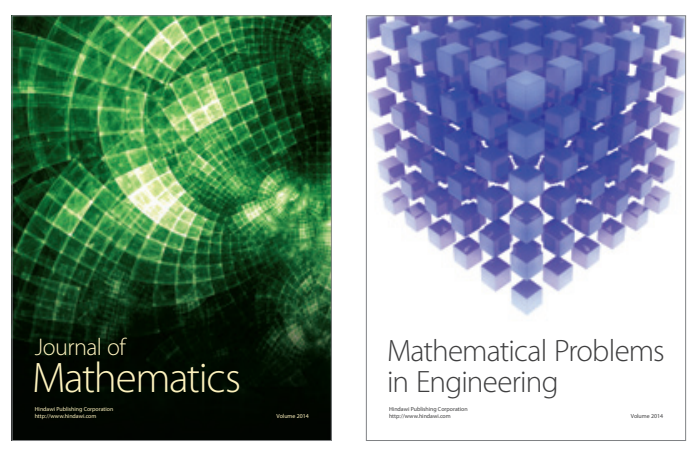

Mathematical Problems in Engineering
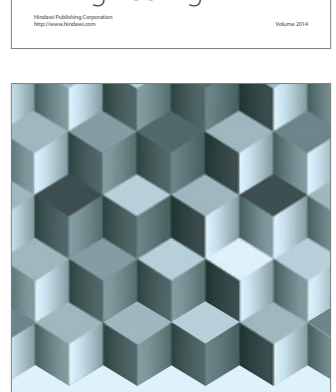

Journal of

Function Spaces
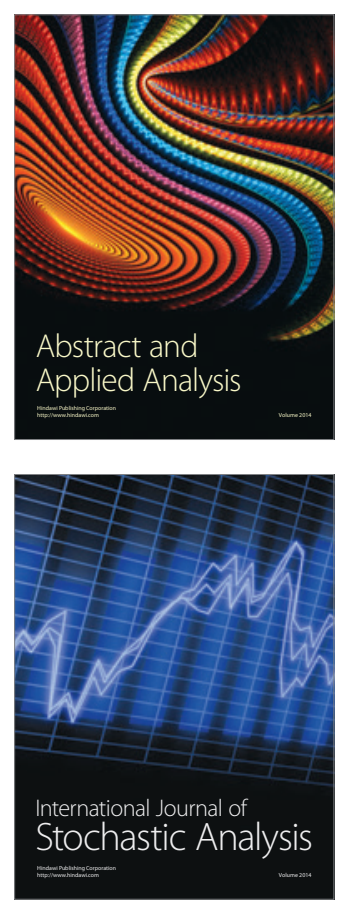

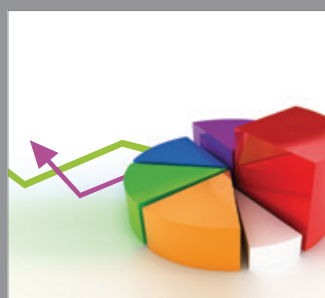

ournal of

Probability and Statistics

Promensencen
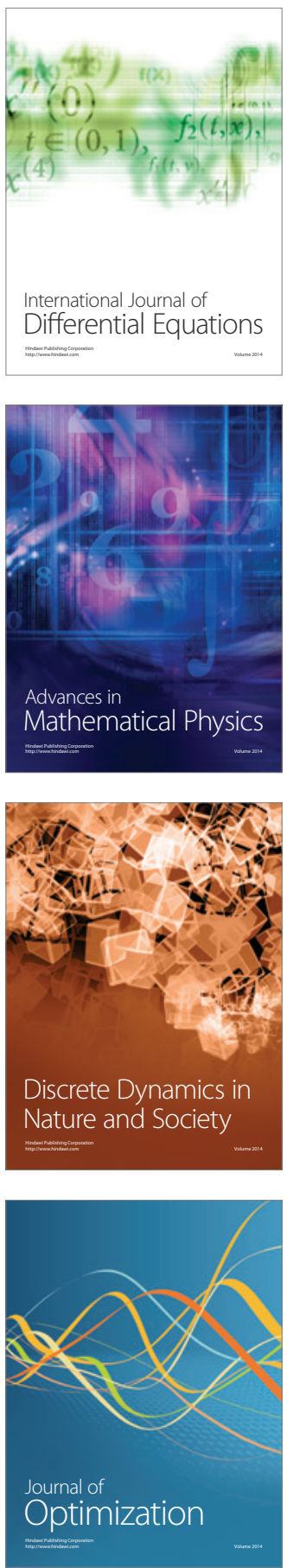